\title{
Clinical Endoscopic and Histological Characteristics of Helicobacter Pylori Positive and Negative Armenian Children with Recurrent Abdominal Pain and/or Dyspepsia
}

Tatevik Shahinyan ( $\nabla$ shahinyan_tatevik@yahoo.com )

Yerevan State Medical University Named after Mkhitar Heratsi https://orcid.org/0000-0003-3788-2839

Gayane Amaryan

Yerevan State Medical University Named after Mkhitar Heratsi

Artashes Tadevosyan

Yerevan State Medical University Named after Mkhitar Heratsi

Christian Peter Braegger

University Children's Hospital Zürich: Universitats-Kinderspital Zurich

Research article

Keywords: RAP, dyspepsia, Helicobacter pylori, children, Armenia

Posted Date: January 19th, 2021

DOI: https://doi.org/10.21203/rs.3.rs-148502/v1

License: (c) (7) This work is licensed under a Creative Commons Attribution 4.0 International License. Read Full License 


\section{Abstract}

\section{Background}

Recurrent abdominal pain (RAP) and dyspepsia are common complaints in children. These symptoms are often associated with Helicobacter pylori ( $\mathrm{Hp}$ )infection. Aim of the present study was to prospectively analyze clinical, endoscopic and histological characteristics of $\mathrm{Hp}+$ and $\mathrm{Hp}$ - children with RAP and/or dyspepsia.

\section{Methods}

Patients aged 2-18 years with RAP and/or dyspepsia, referred for upper endoscopy to Arabkir MC from November 2015 to December 2017, were involved in the study. Histology was assessed according to the updated Sydney system. Gastric and duodenal specimens were stained by modified Giemsa staining for $\mathrm{Hp}$ infection. One antral biopsy was cultured in $\mathrm{Hp}$ selective media.

\section{Results}

150 patients were included into the study: $70.7 \% \mathrm{Hp}+, 29.3 \% \mathrm{Hp}$. Nausea and vomiting were significantly more common in $\mathrm{Hp}+$ patients $(\mathrm{p}<0.05)$. Gastric nodularity $(\mathrm{p}=0.02)$, erosions in the stomach $(\mathrm{p}=0.056)$, and duodenal erosions $(p=0.019)$ were more common in $\mathrm{Hp}+$. Chronic active $(p=0.027)$ and non-active gastritis $(p=0.002)$, cumulative findings of metaplasia/dysplasia/atrophy in the stomach $(p=0.014)$ and chronic non-active duodenitis $(p=0.016)$, were significantly more common in $\mathrm{Hp}+$ patients.

\section{Conclusion}

Hp infection prevalence is high in Armenian children with dyspepsia and/or RAP. Clinical symptoms, endoscopic findings and histopathological findings were significantly different in $\mathrm{Hp}+$ patients as compared to $\mathrm{Hp}$ - patients.

\section{Introduction}

Currently Helicobacter pylori $(\mathrm{Hp})$ infection is a leading cause of inflammatory and malignant diseases of the upper gastrointestinal tract $[1,2,3,4]$.

Prevalence of Hp infection differs and depends on age, geographical, socio-economical, ethnical and other factors $[1,5]$. In developing countries it reaches $70 \%$, and younger ages are more commonly affected $[2,3]$.

$\mathrm{Hp}$ infection is usually acquired during the first years of life in both developing and developed countries. In children it is mainly manifests as gastritis and duodenitis (up to 90-95\%). Peptic ulcer disease (PUD) is observed approximately in $5 \%$ of children younger than 12 years and in $10 \%$ older than 12 years. Gastric malignancies associated with $\mathrm{Hp}$ are very rare in the paediatric age group $[4,6,7,8]$.

Armenia is a country with high incidence of peptic ulcer of stomach and duodenum in patients older than 15 years (100.3/100.000 and 468.2/100.000 respectively in 2018). Penetrating ulcers make 4.08-4.1/100.000. There is also high prevalence of stomach cancer in the adult population (57.7\%) [9]. Although there is no data on prevalence of $\mathrm{Hp}$ infection among children, and limited data in adults in Armenia [10], high level of Hp infection prevalence is assumed in Armenian children. 
Hp eradication therapy aims to prevent complications such as bleeding and penetrating ulcers as well as gastric malignancies. A limiting factor for the treatment success is antibiotic resistance, which differs in developed and developing countries and depends on the spectrum of antibiotic use [11].

\section{Aim Of The Study}

Aim of the present study is to prospectively analyze clinical, endoscopic and histological characteristics of Hp positive and negative Armenian children with recurrent abdominal pain and/or dyspeptic symptoms.

\section{Methods}

230 patients referred to Arabkir MC from November 2015 to December 2017 for upper endoscopy because of recurrent abdominal pain and/or dyspeptic symptoms were involved in the study.

Inclusion criteria were: children and adolescents aged 2-18 years with RAP and/or dyspeptic symptoms, undergoing upper endoscopy.

Exclusion criteria were: Familial Mediterranean fever, coeliac disease, use of non-steroidal anti-inflammatory drugs or proton pump inhibitors up to 2 weeks and antibiotics up to 4 weeks prior to investigation.

A questionnaire was developed for structured collection of the patients history and clinical data. Patients signed a consent form for study which was approved by the Ethics Committee of Yerevan State Medical University (2016). History included information about personal details, family members suffering from GDD, gastric malignancies in the family as well as data on, main complaints, disease onset and eradication treatment before. We included data of 1st and 2nd line relatives suffering from GDD and/or gastric cancer taking into consideration peculiarities of Armenian society - common living with them

All patients underwent esophagogastroduodenoscopy (EGD) under general anesthesia with 4 biopsies by Olympus GIF-XP170N and Olympus GIF-H170 endoscopes. Two biopsies were taken from the antrum (one for rapid urease test and histology, one for $\mathrm{Hp}$ culture), one from the duodenal bulb and one from the distal esophagus. We used the rapid urease test Helpyl (Association of Medicine and Analytics, Russian Federation, http://www.amamed.ru/index.php?i=7). Histology was assessed according to the updated Sydney system (20). Gastric and duodenal specimens were stained by modified Giemsa staining for Hp infection. One of the antral biopsies was cultured in Hp selective media (ChromID, Biomerieux, France) and Columbia agar with 5\% sheep blood (Biomerieux, France).

Patients were divided into 2 groups:

The first group were patients $\mathrm{Hp}+$ by 2 invasive tests. This group was divided in 2 subgroups: subgroup 1 were patients with ulcers, and/or erosions, and/or nodularity in the stomach or duodenum; subgroup 2 were patients with normal appearing mucosa of stomach and duodenum or only superficial changes.

The second group were Hp- patients by 2 invasive tests.

The Statistical Package for Social Science (SPSS version 20) program was used for data analysis. Bivariate analysis was carried out by using the chi-square for comparing categorical variables. A p value $\leq 0.05$ and two 
tailed Fisher exact coefficient value $\leq 0.05$ were considered significant.

\section{Results}

150 patients were included into the study: 106 patients were positive for Hp testing by two invasive tests: 50 males, 56 females, aged 2-18 years (mean age $9.67 \pm 0.37$ years). 44 patients were Hp negative: 20 males, 24 females, aged $2-18 y$, mean age $8.13 \pm 0.58)$.

Preschool children aged 2-5y made 15 (14.2\%) of the Hp + group, 6-10y old children 48 (45.2\%), 11-14y old children 31 (29.2\%), and 15-17y old adolescents 12 (11.3\%).

Distribution of gender in the groups was: $\mathrm{Hp}+$ male/female 50/56 and Hp- 56/24, shown in the Fig. 2, there was no statistically significant difference between gender concerning Hp presence $(p>0.05)$

Comparative analysis of number of $\mathrm{Hp}+$ patients from urban area (capital Yerevan and regional towns) and country side did not show any statistical difference in distribution of Hp (Fig. 3).

\section{Clinical Data Comparison}

Gastric cancer was not significantly more common in families of $\mathrm{Hp}+$ patients $(\mathrm{F}=1)$, however most of the family members of $\mathrm{Hp}+$ group had dyspeptic symptoms and/or abdominal pain, but were not investigated $(\mathrm{F}=0.001)$ (Table 1).

The most common symptoms in both groups were recurrent epigastric pain, nausea and vomiting. Distribution of symptoms in the two groups is shown in Table 2. Nausea and vomiting were significantly more common in $\mathrm{Hp}+$ patients $(p<0.05)$.

When we have compared 2 subgroups in the $\mathrm{Hp}+$ group divided by the severity of endoscopic changes, Regurgitation and night time pain were significantly more common in $\mathrm{Hp}+$ patients with stomach and duodenal ulcerative and aphthous erosive lesions (Table 3).

Analysis of endoscopic data has shown that gastric nodularity, erosions in the stomach, erosive lesions in the duodenum are significantly more common in $\mathrm{Hp}+$ compared to $\mathrm{Hp}$ - patients (Table 4). Besides of $7 \mathrm{Hp}+(15.9 \%)$ patients, 2 (4.5\%) of Hp- patients had ulcers in the stomach and duodenum.

Histological data comparison showed that chronic active 10 (9.4\%) and non-active gastritis 85 (80.2\%), chronic non-active duodenitis 49 (46.2\%) and cumulative findings of metaplasia/ dysplasia/atrophy in the stomach 10 (9.4\%) are statistically more common histologic signs of $\mathrm{Hp}$ infection in Armenian children (Table 5).

The comparison of significant histologic changes in $\mathrm{Hp}+$ patients with superficial and ulcerative/erosive lesions did not show any statistical difference (Table 6) $(p>0.05)$.

\section{Discussion}

This is the first study assessing clinical, endoscopic and histological characteristics of Hp + and Hp- Armenian children with recurrent abdominal pain and/or dyspepsia. 
Prevalence of $\mathrm{Hp}$ in symptomatic children differs from country to country: $34.6 \%$ in Ethiopia (15), 25\% in Hon Kong (14), 24.5\% in Bulgaria (13), 64.6\% in Egypt (16). The prevalence is mainly depending on socio-economic status and number of family members. There is only one study assessing seroprevalence of Hp infection in symptomatic adults with dyspeptic symptoms in Armenia showing of $49 \%$ being positive [10]. In our cohort of patients with recurrent abdominal pain and/or dyspepsia Helicobacter pylori was diagnosed in $70.6 \%$. This high prevalence might be explained by the fact of acquiring infection in the childhood, developing status of Armenia and intrafamilial distribution of infection (high number of family members with gastritis, PUD and dyspeptic symptoms).

There are different concepts on decision of making endoscopy in pediatric patients with repeated or chronic abdominal pain and dyspepsia. Hyams JS et al. found that duration of vomiting and other dyspeptic symptoms more than 1 year were risk factors for mucosal inflammation of upper GI tract [12]. Other study suggested importance of EGD in patients with symptom duration more than 6 months, severe symptoms affecting sleep and family history of peptic ulcer disease or Hp infection [22].

Our patients were referred to medical attention with symptoms persisting median more than a year in both groups. According to the current literature data, there is no significant difference in symptoms of Hp positive vs Hp negative children shown in symptomatic pediatric population $[13,14,15,16]$. In contrast to published studies from other countries our study showed that night time abdominal pain and regurgitaion were statistically more common in $\mathrm{Hp}+$ children with PUD and/or aphthous lesions in the upper GI tract.

Antral nodularity is one of the signs of $\mathrm{Hp}$ associated gastritis and maybe associated with higher grade of gastritis in children $[23,25,26]$. According to our data erosive lesions in the stomach and duodenum were statistically more common endoscopic findings in $\mathrm{Hp}+$ patients, gastric nodularity were exclusively found in $\mathrm{Hp}+$ group.

Low incidence of ulcers in Hp positive children was reported in Chinese [17] 7.2\% and European (6.8\%) pediatric patients [4]. In contrast to it, in developing countries PUD prevalence in Hp positive children reaches 33.2\% [18, 19]. Our study showed low incidence of PUD in Hp + Armenian children, which might be explained by treatment received before admission. $2 \mathrm{Hp}$ - patients had ulcers, probably due to GI bleeding or false negative Hp test.

$\mathrm{Hp}$ infection has been reported was significantly associated with chronic (88.5\%) and active (63\%) gastritis [23]. Data obtained by Canan 0 . et al, showed that in two third of the patients with nonorganic dyspepsia had normal histological data, while one third had mild or chronic non-active inflammation of the mucosa [20]. Similarly in our cohort of patients the main histological findings in $\mathrm{Hp}+$ patients were chronic active and non-active gastritis and duodenitis, while in $\mathrm{Hp}$ - patients mainly histologically normal mucosa was seen. Nevertheless more than half of Hp- negative patients had chronic non-active inflammation in the stomach.

Our study showed that serious histologic changes were exclusively seen $\mathrm{Hp}+$ children, and equally observed in both patients with ulcerative/aphthous and superficial changes. This is contrast with the review analyzing atrophy and intestinal metaplasia in children, where different rates are mentioned and this changes are not always connected with Hp infection [24].

\section{Conclusion}


Hp prevalence is high in Armenian children with dyspepsia and/or recurrent abdominal pain (70.6\%). Nausea and vomiting are significantly more common in $\mathrm{Hp}+$ patients $(\mathrm{p}<0.05)$, while in patients having night time pain and regurgitation, ulcerative and/or erosive lesion by EGDS are observed more likely. Significant histological changes of the mucosa of the stomach such as atrophy, metaplasia or dyplasia were only observed in $\mathrm{Hp}+\mathrm{patients.}$ However, histologic changes do not correlate with the severity of the endoscopic findings.

\section{Abbreviations}

GDD - gastroduodenal disease

Hp - Helicobacter pylori

Hp- - Helicobacter pylori negative

Hp+ - Helicobacter pylori positive

RAP - Recurrent abdominal pain

PUD - Peptic ulcer disease

\section{Declarations}

Funding: The study was partially funded by Research Grant of Zurich Children's Hospital, Switzerland. Salary of investigators was paid by Arabkir Medical Center - institute of Child and Adolescent Health

Conflicts of interest/Competing interests: The authors declare that they have no conflict of interest.

Ethics approval: This study was performed in line with the principles of the Declaration of Helsinki. Approval was granted by the Ethics Committee of Yerevan State Medical University Named after Mkhitar Heratsi (Date 19.12.2017 /No. 4).

Consent to participate: Informed consent was obtained from the parents.

Consent for publication: N/A

Availability of data and material: All data and materials as are available in electronical database and could be shared upon request.

Code availability: N/A

Authors' contributions: All authors contributed to the study conception and design. Material preparation, data collection and analysis were performed by Tatevik Shahinyan, Artashes Tadevosyan, Gayane Amaryan and Christian Braegger. The first draft of the manuscript was written by Tatevik Shahinyan and all authors commented on previous versions of the manuscript. All authors read and approved the final manuscript.

\section{References}

1. Wenming, Wu, et al., Recent Insights into Antibiotic Resistance in Helicobacter pylori Eradication, Gastroenterology Research and Practice, Volume 2012, Article ID 723183, doi:10.1155/2012/723183.

2. Matjaz, Homan, et all, Helicobacter pylori in Pediatrics, Helicobacter, ISSN 1523-5378, doi: 10.1111/j.15235378.2012.00982.x. 
3. Jones NL, Koletzko S, Goodman K, et al. Joint ESPGHAN/NASPGHAN Guidelines for the management of Helicobacter pylori in children and adolescents (update 2016). J PediatrGastroenterolNutr. 2017;64(6):9911003.

4. Koletzko S, et all, Prospective multicentre study on antibiotic resistance of Helicobacter pylori strains obtained from children living in Europe, Gut 2006;55:1711-1716.

5. Global Guideline WGO. H. pylori, August 2010.

6. Kurugoglu S, Mihmanli I, Celkan T, et al. Radiological features in paediatric primary gastric MALT lymphoma and association with Helicobacter pylori. Pediatr Radiol. 2002;32:82-7.

7. Moschovi M, Menegas D, Stefanaki K, et al. Primary gastric Burkitt lymphoma in childhood: associated with Helicobacter pylori? Med Pediatr Oncol. 2003;41:444-7.

8. Bauer B, et al., The Human Gastric Pathogen Helicobacter pylori and Its Association with Gastric Cancer and Ulcer Disease, Hindawi Publishing Corporation, Ulcers, Volume 2011, Article ID 340157, 23 pages.

9. Annual. Health statistics for 2019, Yerevan, Armenia.

10. Gemilyan M, et al. Prevalence of Helicobacter pylori infection and antibiotic resistance profile in Armenia. Gut Pathog. 2019;11:28. https://doi.org/10.1186/s13099-019-0310-0.

11. Meґgraud F. et all Helicobacter pylori, Resistance to Antibiotics in Europe and Its Relationship to Antibiotic Consumption. Gut. 2013;62(1):34-42.

12. Hyams JS, Davis P, Sylvester FA, et al. Dyspepsia in children and adolescents: a prospective study. J Pediatr Gastroenterol Nutr. 2000;30:413-8.

13. Boyanova $L$, et al., Prevalence of Helicobacter pylori is still high among symptomatic Bulgarian children, Acta Microbiologica et Immunologica Hungarica, Volume 66: Issue 2, p. 255-260, https://doi.org/10.1556/030.65.2018.053.

14. Tang MYL, Chung PHY, Chan HY, Tam PKH, Wong KK. Recent trends in the prevalence of Helicobacter pylori in symptomatic children: a 12-year retrospective study in a tertiary centre. J Pediatr Surg. 2019;54(2):255-7.

15. Shiferaw G, Abera D. Magnitude of Helicobacter pylori and associated risk factors among symptomatic patients attending at Jasmin internal medicine and pediatrics specialized private clinic in AddisAbaba city, Ethiopia. BMC Infect Dis. 2019;19(1):118.

16. Galal, et al., Helicobacter pylori among symptomatic Egyptian children: prevalence, risk factors, and effect on growth, J Egypt Public Health Assoc (2019) 94:17 https://doi.org/10.1186/s42506-019-0017-6.

17. Tang Z, Shi J, Ji M, Shi P, Huang Z, Huang Y. The characteristics of 83 giant peptic ulcers in Chinese children: evaluation and follow- up. Saudi J Gastroenterol. 2018;24(6):360-4.

18. Velmishi V, Cekodhima G, Cekodhima A, Cullufi EDervishi,P, Peptic ulcer disease in Albanian children: The role of Helicobacter pylori, Global Advanced Research Journal of Microbiology (ISSN: 2315-5116) Vol. 3(8) pp. 127-132, October, 2014.

19. Mohammad Issa El Mouzan and Asaad Mohammad Abdullah. Peptic Ulcer Disease in Children and Adolescents, Journal of Tropical Pediatrics, Vol. 50, No. 6.

20. Canan O, Ozcay F, et al., Value of the Likert Dyspepsia Scale in Differentiation of Functional and Organic Dyspepsia in Children, JPGN 2011;52: 392-398.

21. Jour S, Manfred M, et al., The Updated Sydney System: Classification and Grading of Gastritis as the Basis of Diagnosis and Treatment, Canadian Journal of Gastroenterology, Pulsus Group Inc 367832, 15-2291-2789, 
https://doi.org/10.1155/2001/367832, 10.1155/2001/367832.

22. Guariso G, Meneghel A, Dalla Pozza LV, et al. Indications to upper gastrointestinal endoscopy in children with dyspepsia. J Pediatr Gastroenterol Nutr. 2010;50:493-9.

23. Mazigh Mrad S, Abidi K, Brini I, Boukthir S. and A. Sammoud Nodular gastritis: an endoscopic indicator of Helicobacter Pylori infection in children. La Tunisie Médicale. 2012;90(11):789-92.

24. Dimitrov G, Gottrand F. Does gastric atrophy exist in children? World J Gastroenterol. 2006;12:6274-9.

25. Luzza F, Pensabene L, Imeneo M, Mancuso M, Contaldo A, Giancotti L, et al. Antral nodularity identifies children infected with Helicobacter pylori with higher grades of gastric inflammation, Gastrointestinal endoscopy, V 53, N. 1, 2001, doi:10.1067/mge.2001.111043.

26. Łazowska-Przeorek I, et al. Value of Antral Nodularity for the Diagnosis of Helicobacter pylori Infection in Children. Med Sci Monit. 2015;21:1827-30. DOI:10.12659/MSM.893467.

\section{Tables}

Table 1

Family history

\begin{tabular}{|llllllll|}
\hline Relatives & HP+ & $\%$ & HP- & $\%$ & Odds Ratio & Cl & P \\
\hline Cancer & 3 & 2.8 & 1 & 2.3 & 1.26 & $0.13-12.38$ & $\mathrm{~F}=1$ \\
\hline PUD & 20 & 18.7 & 4 & 9 & 2.32 & $0.75-7.25$ & $\mathrm{~F}>0.05$ \\
\hline GD & 23 & 21.7 & 5 & 11.4 & 2.16 & $0.76-6.11$ & $\mathrm{p}>0.05$ \\
\hline Symptoms & 36 & 34 & 4 & 9 & 5.1 & $1.71-15.51$ & $\mathrm{~F}=0.001$ * \\
\hline Total & 82 & 70.7 & 14 & 29.3 & 7.32 & $3.35-15.98$ & $\mathrm{~F}=0.000$ * \\
\hline *statistically significant observation & & & & \\
\hline
\end{tabular}


Table 2

Symptoms

\begin{tabular}{|llllllllll|}
\hline & Total & $\%$ & HP+ & $\%$ & HP- & $\%$ & OR & Cl & P \\
\hline Nausea & 78 & $52.0 \%$ & 60 & $56.6 \%$ & 18 & $40.9 \%$ & 1.88 & $1.001-4.015$ & $p<0.05^{\star}$ \\
\hline Vomiting & 39 & $26.0 \%$ & 29 & $27.4 \%$ & 10 & $22.7 \%$ & 1.28 & $0.56-2.92$ & $p>0.05$ \\
\hline Dysphagia & 2 & $1.3 \%$ & 1 & $0.9 \%$ & 1 & $2.3 \%$ & 0.41 & $0.03-6.70$ & $p>0.05$ \\
\hline Regurgitation & 31 & $20.7 \%$ & 22 & $20.8 \%$ & 9 & $20.5 \%$ & 1.02 & $0.43-2.43$ & $p>0.05$ \\
\hline Heartburn & 18 & $12.0 \%$ & 16 & $15.1 \%$ & 2 & $4.5 \%$ & 3.71 & $0.82-16.98$ & $p<0.05^{\star}$ \\
\hline Abdominal pain & 123 & $82.0 \%$ & 87 & $82.1 \%$ & 36 & $81.8 \%$ & 1.02 & $0.41-2.54$ & $p>0.05$ \\
\hline Halitosis & 17 & $11.3 \%$ & 12 & $11.3 \%$ & 5 & $11.4 \%$ & 1 & $0.33-3.02$ & $p>0.05$ \\
\hline Night time pain & 17 & $11.3 \%$ & 13 & $12.3 \%$ & 4 & $9.1 \%$ & 1.39 & $0.43-4.55$ & $p>0.05$ \\
\hline Melena & 3 & $2.0 \%$ & 3 & $2.8 \%$ & 0 & $0.0 \%$ & -1 & N/A & $p>0.05$ \\
\hline Constipation & 20 & $13.3 \%$ & 13 & $12.3 \%$ & 7 & $15.9 \%$ & 0.74 & $0.27-2.00$ & $p>0.05$ \\
\hline
\end{tabular}


Table 3

Symptoms: comparison of endoscopic Hp + group subgroups

\begin{tabular}{|c|c|c|c|c|c|c|c|}
\hline \multirow{2}{*}{$\begin{array}{l}\text { Complaint } \\
\text { Total }\end{array}$} & \multicolumn{2}{|c|}{ All patients } & \multicolumn{2}{|c|}{$\begin{array}{l}\text { Endoscopic ulcer/ aphthous } \\
\text { erosions/nodular }\end{array}$} & \multicolumn{2}{|c|}{$\begin{array}{l}\text { Superficial changes / } \\
\text { normal mucosa }\end{array}$} & \\
\hline & $(106)$ & $100 \%$ & (59) & $100 \%$ & (47) & $100 \%$ & \\
\hline Nausea & 60 & $56.6 \%$ & 35 & $59.3 \%$ & 25 & $53.2 \%$ & $\begin{array}{l}p> \\
0.05\end{array}$ \\
\hline Vomiting & 29 & $27.4 \%$ & 18 & $30.5 \%$ & 11 & $23.4 \%$ & $\begin{array}{l}p> \\
0.05\end{array}$ \\
\hline Bloody vomit & 2 & $1.9 \%$ & 1 & $1.7 \%$ & 1 & $2.1 \%$ & $\begin{array}{l}F> \\
0.05\end{array}$ \\
\hline Dysphagia & 1 & $0.9 \%$ & 0 & $0.0 \%$ & 1 & $2.1 \%$ & $\begin{array}{l}F> \\
0.05\end{array}$ \\
\hline Regurgitation & 22 & $20.8 \%$ & 16 & $27.1 \%$ & 6 & $12.8 \%$ & $\begin{array}{l}\mathrm{p}< \\
0.05^{\star}\end{array}$ \\
\hline Heartburn & 16 & $15.1 \%$ & 10 & $16.9 \%$ & 6 & $12.8 \%$ & $\begin{array}{l}p> \\
0.05\end{array}$ \\
\hline $\begin{array}{l}\text { Rec. } \\
\text { epigastric } \\
\text { pain }\end{array}$ & 87 & $82.1 \%$ & 49 & $83.1 \%$ & 38 & $80.9 \%$ & $\begin{array}{l}p> \\
0.05\end{array}$ \\
\hline Halitosis & 12 & $11.3 \%$ & 7 & $11.9 \%$ & 5 & $10.6 \%$ & $\begin{array}{l}p> \\
0.05\end{array}$ \\
\hline $\begin{array}{l}\text { Night time } \\
\text { pain }\end{array}$ & 13 & $12.3 \%$ & 10 & $16.9 \%$ & 3 & $6.4 \%$ & $\begin{array}{l}\mathrm{F}= \\
0.054^{\star}\end{array}$ \\
\hline Melena & 3 & $2.8 \%$ & 3 & $5.1 \%$ & 0 & $0.0 \%$ & $\begin{array}{l}F> \\
0.05\end{array}$ \\
\hline Constipation & 13 & $12.3 \%$ & 7 & $11.9 \%$ & 6 & $12.8 \%$ & $\begin{array}{l}p> \\
0.05\end{array}$ \\
\hline
\end{tabular}


Table 4

Endoscopic data

\begin{tabular}{|lllllllll|}
\hline & EGDS & Total & $\%$ & HP+ & $\%$ & HP- & $\%$ & P \\
\hline Esophagus & Normal mucosa & 141 & $94.0 \%$ & 100 & $94.3 \%$ & 41 & $93.2 \%$ & F $>0.05$ \\
& Hyperaemia & 8 & $5.3 \%$ & 5 & $4.7 \%$ & 3 & $6.8 \%$ & $\mathrm{p}>0.05$ \\
\hline & Erosions & 1 & $0.7 \%$ & 1 & $0.9 \%$ & & $0.0 \%$ & $\mathrm{p}>0.05$ \\
\hline Stomach & Normal mucosa & 9 & $6.0 \%$ & 4 & $3.8 \%$ & 5 & $11.4 \%$ & $\mathrm{~F}>0.05$ \\
\hline & Superficial & 94 & $62.7 \%$ & 61 & $57.5 \%$ & 33 & $75.0 \%$ & $0.02^{*}$ \\
\hline & Nodular & 12 & $8.0 \%$ & 12 & $11.3 \%$ & & $0.0 \%$ & $0.006^{*}$ \\
\hline & Erosions & 33 & $22.0 \%$ & 27 & $25.5 \%$ & 6 & $13.6 \%$ & $0.056^{*}$ \\
\hline & Ulcers & 2 & $1.3 \%$ & 2 & $1.9 \%$ & 0 & $0.0 \%$ & $\mathrm{~F}>0.05$ \\
\hline Nuodenum & Normal mucosa & 10 & $6.7 \%$ & 5 & $4.7 \%$ & 5 & $11.4 \%$ & $\mathrm{p}>0.05$ \\
\hline & Superficial & 79 & $52.7 \%$ & 50 & $47.2 \%$ & 29 & $65.9 \%$ & $0.019 *$ \\
\hline & Erosions & 52 & $34.7 \%$ & 44 & $41.5 \%$ & 8 & $18.2 \%$ & $0.029 *$ \\
\hline Ulcers & 9 & $6.0 \%$ & 7 & $6.6 \%$ & 2 & $4.5 \%$ & $\mathrm{p}>0.05$ \\
\hline
\end{tabular}


Table 5

Histological data comparison in $\mathrm{Hp}+$ and $\mathrm{Hp}$ - group

\begin{tabular}{|c|c|c|c|c|c|c|c|c|}
\hline & Histology & Total & $\%$ & $\mathrm{HP+}$ & $\%$ & HP- & $\%$ & $p$ \\
\hline \multirow[t]{7}{*}{ Stomach } & Normal & 30 & $20.0 \%$ & 11 & $10.4 \%$ & 19 & $43.2 \%$ & $0.000^{*}$ \\
\hline & Chronic non-active & 110 & $73.3 \%$ & 85 & $80.2 \%$ & 25 & $56.8 \%$ & $0.002^{\star}$ \\
\hline & Chronic active & 10 & $6.7 \%$ & 10 & $9.4 \%$ & 0 & $0.0 \%$ & $\begin{array}{l}F= \\
0.027 *\end{array}$ \\
\hline & $\begin{array}{l}\text { Metaplasia/ } \\
\text { dysplasia/atrophy }\end{array}$ & 10 & $6.7 \%$ & 10 & $9.4 \%$ & 0 & $0.0 \%$ & $0.014^{\star}$ \\
\hline & Metaplasia & 2 & $1.3 \%$ & 2 & $1.9 \%$ & 0 & $0.0 \%$ & $F>0.05$ \\
\hline & Dysplasia & 3 & $2.0 \%$ & 3 & $2.8 \%$ & 0 & $0.0 \%$ & $F>0.05$ \\
\hline & Atrophy & 5 & $3.3 \%$ & 5 & $4.7 \%$ & 0 & $0.0 \%$ & $F>0.05$ \\
\hline \multirow[t]{8}{*}{ Duodenum } & Normal & 77 & $51.3 \%$ & 46 & $43.4 \%$ & 31 & $70.5 \%$ & $0.001^{*}$ \\
\hline & Chronic non-active & 61 & $40.7 \%$ & 49 & $46.2 \%$ & 12 & $27.3 \%$ & $0.016^{*}$ \\
\hline & Chronic active & 8 & $5.3 \%$ & 7 & $6.6 \%$ & 1 & $2.3 \%$ & $F>0.05$ \\
\hline & & 4 & $2.7 \%$ & 4 & $3.8 \%$ & 0 & $0.0 \%$ & \\
\hline & Acute & & & & & & & $F>0.05$ \\
\hline & Metaplasia/dysplasia & 12 & $8.0 \%$ & 9 & $8.5 \%$ & 3 & $6.8 \%$ & $F>0.05$ \\
\hline & Metaplasia & 11 & $7.3 \%$ & 8 & $7.5 \%$ & 3 & $6.8 \%$ & $F>0.05$ \\
\hline & Dysplasia & 1 & $0.7 \%$ & 1 & $0.9 \%$ & 0 & $0.0 \%$ & $F>0.05$ \\
\hline
\end{tabular}

Table 6

Histological data comparison in 2 subgroups of $\mathrm{Hp}+$ group

\begin{tabular}{|c|c|c|c|c|c|c|c|c|}
\hline \multirow[t]{2}{*}{ Atrophy/metaplasia/dysplasia } & \multirow[t]{2}{*}{ Total } & \multicolumn{2}{|c|}{$\begin{array}{l}\text { Ulcerative/aphthous } \\
\text { erosions/nodularity }\end{array}$} & \multicolumn{2}{|c|}{$\begin{array}{l}\text { Superficial } \\
\text { changes/normal } \\
\text { mucosa }\end{array}$} & \multirow[t]{2}{*}{ p } & \multirow[t]{2}{*}{ OR } & \multirow[t]{2}{*}{$\mathrm{Cl}$} \\
\hline & & $\mathbf{N}$ & $\%$ & $\mathbf{N}$ & $\%$ & & & \\
\hline Stomach & 10 & 5 & 8.47 & 5 & 10.64 & $\overrightarrow{0} .05$ & 0.78 & $0.21-86$ \\
\hline Duodenum & 11 & 9 & 15.25 & 2 & 4.26 & $\begin{array}{l}> \\
0.05\end{array}$ & 4.05 & $\begin{array}{l}0.83- \\
19.74\end{array}$ \\
\hline
\end{tabular}


Figures

\section{Distribution by age groups}

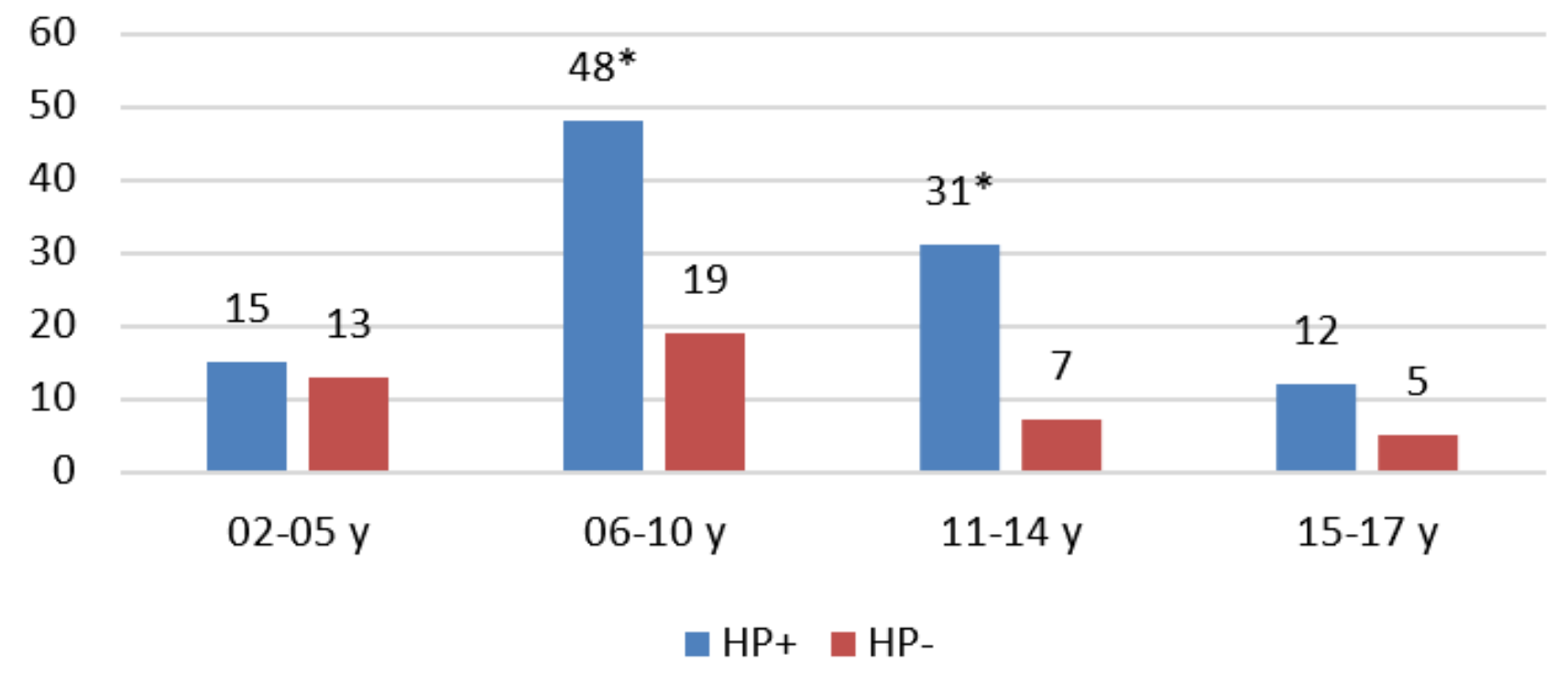

Figure 1

Distribution by age groups *statistically significant observation $p<0.05$

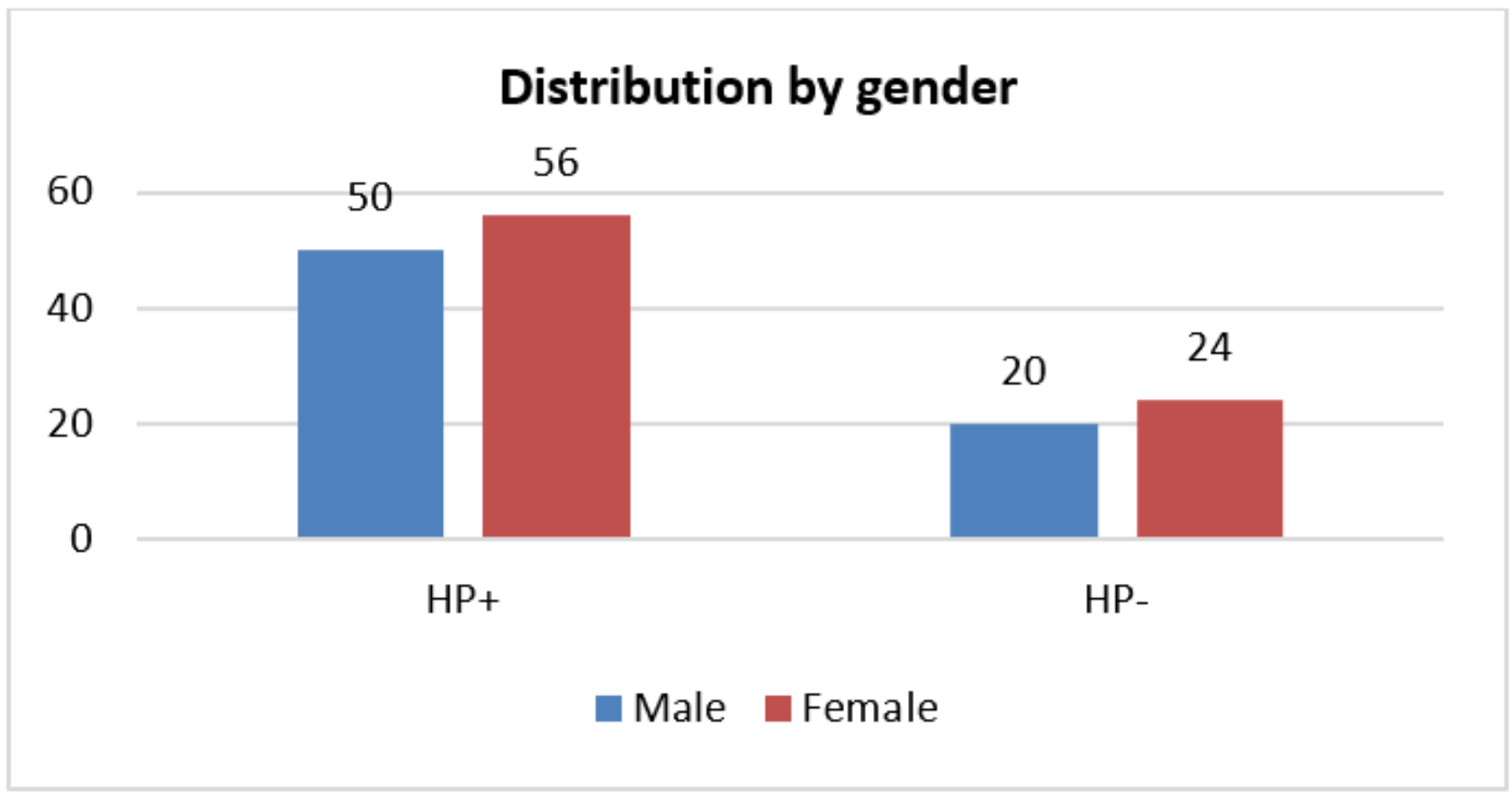

Figure 2 
Distribution by gender

\section{The place of inhabitance}

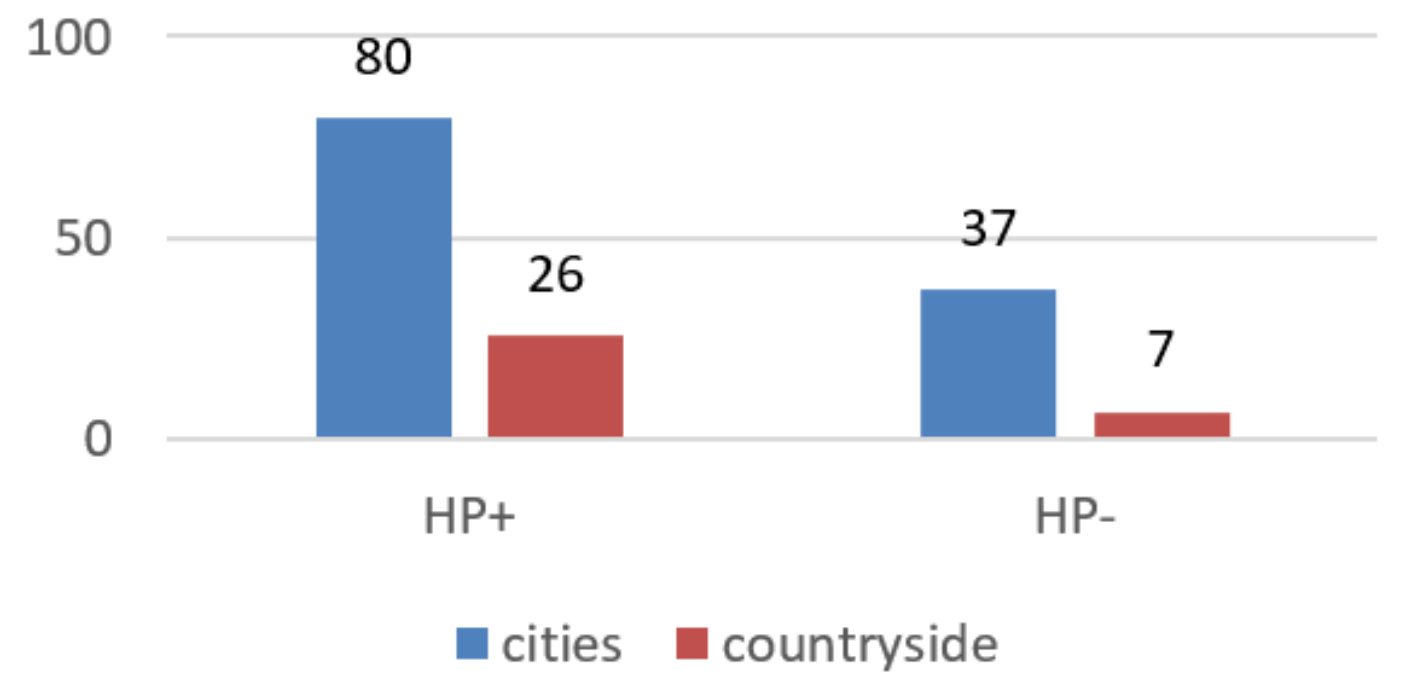

Figure 3

Distribution of patients by place of inhabitance 